\title{
A Mini-Review of Relationships Between Cannabis Use and Neural Foundations of Reward Processing, Inhibitory Control and Working Memory
}

\author{
Kristen P. Morie ${ }^{1,2}$ and Marc N. Potenza ${ }^{1,2,3,4,5 *}$ \\ ${ }^{1}$ Department of Psychiatry, Yale University School of Medicine, New Haven, CT, United States, ${ }^{2}$ Child Study Center, Yale \\ University School of Medicine, New Haven, CT, United States, ${ }^{3}$ Connecticut Mental Health Center, New Haven, CT, \\ United States, ${ }^{4}$ Connecticut Council on Problem Gambling, Wethersfield, CT, United States, ${ }^{5}$ Department of Neuroscience, \\ Yale University School of Medicine, New Haven, CT, United States
}

OPEN ACCESS

Edited by:

Thomas Heffernan,

Northumbria University,

United Kingdom

Reviewed by:

Hitoshi Morikawa,

University of Texas at Austin,

United States

Liangsuo Ma,

Virginia Commonwealth University,

United States

*Correspondence:

Marc N. Potenza

marc.potenza@yale.edu

Specialty section:

This article was submitted to

Addictive Disorders,

a section of the journal

Frontiers in Psychiatry

Received: 22 January 2021

Accepted: 29 March 2021

Published: 22 April 2021

Citation:

Morie KP and Potenza MN (2021) A Mini-Review of Relationships Between

Cannabis Use and Neural

Foundations of Reward Processing,

Inhibitory Control and Working

Memory. Front. Psychiatry 12:657371.

doi: 10.3389/fpsyt.2021.657371
Cannabis is commonly used, and use may be increasing in the setting of increasing legalization and social acceptance. The scope of the effects of cannabis products, including varieties with higher or lower levels of $\Delta$ 9-tetrahydrocannabinol (THC) or cannabidiol (CBD), on domains related to addictive behavior deserves attention, particularly as legalization continues. Cannabis use may impact neural underpinnings of cognitive functions linked to propensities to engage in addictive behaviors. Here we consider these neurocognitive processes within the framework of the dual-process model of addictions. In this mini-review, we describe data on the relationships between two main constituents of cannabis (THC and CBD) and neural correlates of reward processing, inhibitory control and working memory.

Keywords: sustance-related disorders, addictive behaviors, cannabis, cannabidiol, cognition, reward, impulsiveness

\section{INTRODUCTION}

Cannabis is widely used. The 2018 Monitoring the Future survey indicated that approximately one-fifth of adolescents had tried cannabis by 12th grade (1), with frequencies of past-month use having increased over several years (2). There has been increasing legalization of cannabis and cannabis-derived products (3), and a commensurate increase in novel ways to consume these products, including edibles, pills and vaping (4-6). Novel routes of consumption have accompanied products with varying amounts of $\Delta 9$-tetrahydrocannabinol (THC) and cannabidiol (CBD), including ones that contain only CBD, such as oils or gummies. Table $\mathbf{1}$ illustrates several of these products, and it is likely that usage rates and formulations will continue to change as new products are developed.

Increases in legalization and multiple consumption methods have accompanied changes in perceptions, with more individuals perceiving marijuana products as safe and non-addictive $(7,8)$. However, individuals with heavier use of cannabis and cannabis use disorder (CUD) typically report lower qualities of life (9). Longer-term ramifications of use of different cannabis products, specifically on neural and cognitive processes associated with engagement in addictive behaviors, remain understudied. As increasing legalization looms and use of cannabis products becomes increasingly socially acceptable, understanding potential effects of cannabis use on the brain, 
and how alternate methods of use or different cannabinoid products may affect the brain and propensities for addictive engagement, is particularly important.

Recent reviews of cannabis use have focused on epidemiological considerations and how use patterns have changed as legalization continues (10), and the ramifications of cannabis use on multiple domains examined using fMRI (11). Differences between THC and CBD have also been reviewed, with a focus on how acute administration may effect blood flow and neural activation (12). Here, we review data specifically relevant to the dual-process model of addiction on how cannabis may impact domains associated with reward processing and inhibitory control, as well as working memory. Each of these domains has been linked to addictive behaviors $(13,14)$. We review select preclinical, behavioral and brain imaging research using functional magnetic resonance imaging (fMRI) and additionally consider electroencephalography (EEG), which has not been included in past imaging-centered reviews of effects of cannabis. We also discuss differences between THC and CBD, which have very different effects.

\section{THC AND CBD}

Cannabis contains multiple cannabinoids, and the two that have received most research attention are THC (15) and CBD (16). THC is a psychoactive compound, with neurotropic effects including "highs" (17), anxiety (18), and psychosis (19, 20 ), the risk for which is increased with higher quantities of THC consumed (21). CBD acts as an indirect antagonist of THC's effects (16). CBD binds less tightly than THC to $\mathrm{CB} 1$ and $\mathrm{CB} 2$ receptors, and, while acute administration of THC often results in anxiety, dysphoria, and increased heart rate, effects of acute administration of $\mathrm{CBD}$ and placebo on these measures were indistinguishable, not generating significant changes (22). CBD is a negative allosteric modulator of the CB1 receptor (23), modifying the receptor's affinity for THC and potentially reducing THC's effects (24). Brief explanations for the mechanisms of action for THC and CBD and their binding potential are illustrated in Table 2, although it should be mentioned that binding affinities for these substances do not always correspond to their effects on cell action (29). CBD products, such as oils or tinctures, are typically derived from the "hemp" strain of the cannabis plant (Chemovar type III), which contains $0.3 \%$ or less THC by weight, while THC products are typically derived from high THC strains (Chemovar type I). There is little evidence of CBD alone having strong abuse liability (30-32). Despite the burgeoning use of cannabis-derived oils, tinctures and edibles in specific forms or with specific formulations focused upon THC or CBD, investigations of specific cannabinoids on domains of working memory, reward processing and inhibitory control are relatively scarce.

\section{INHIBITORY CONTROL, REWARD PROCESSING, WORKING MEMORY AND THE DUAL PROCESS MODEL OF ADDICTION}

The dual-process model of addiction suggests that sensitization of reward circuitry is coupled with poorer top-down control of reward systems, resulting in poorly controlled behaviors and drug use (33). Top-down control reflects executive functions, such as inhibitory control and working memory. Poor inhibitory control and working memory coupled with increased reward motivation may reflect imbalances in maturational trajectories of reward-related regions (34), such as the striatum, and regions involved in reward-related impulse regulation, like the prefrontal cortex (PFC), both of which are implicated in addictive disorders $(14,35)$. Effects on cognition may further increase risk for engagement in addictive behaviors (36), and potential effects of cannabis on these areas of brain functioning may be reflected in the "gateway drug" hypothesis wherein marijuana precedes and predisposes to other illicit drug use (37). How cannabis use may influence domains of reward processing, inhibitory control and cognitive functioning has typically focused on combustible cannabis. Alternative methods of use, including vaping and edibles, have been less well studied. Understanding effects of cannabis use, and additionally the potential effects of chronic use of THC or CBD concentrates, is particularly important given ongoing legalization efforts.

TABLE 1 | Examples of methods of cannabis administration.

\begin{tabular}{|c|c|c|c|}
\hline & Combustible & Edibles & Vape/dab \\
\hline Product/method & Smoking joints, pipes & $\begin{array}{l}\text { Gummies, capsules, pills, } \\
\text { cannabis-infused food and drink }\end{array}$ & Oils, shatter/butter \\
\hline \multirow{2}{*}{ THC or CBD content } & $\begin{array}{l}\text { Chemovar Type II approximate } \\
\text { 1:1 ratio THC/CBD }\end{array}$ & $\begin{array}{l}40-50 \mathrm{mg} \text { THC per day (medical } \\
\text { grade pain relief) to } 100 \mathrm{mg} \\
\text { (recreational users with high } \\
\text { tolerance) }\end{array}$ & Shatter/butter up to $80-90 \%$ THC \\
\hline & $\begin{array}{l}\text { Chemovar Type III <0.3\% THC, } \\
\text { CBD-Dominant }\end{array}$ & $\begin{array}{l}\text { Products also include CBD only } \\
\text { with essentially no THC (derived } \\
\text { from Chemovar type III) }\end{array}$ & $\begin{array}{l}\text { CBD oils and CBD shatter (derived } \\
\text { from Chemovar Type III) }\end{array}$ \\
\hline
\end{tabular}




\section{CANNABIS AND WORKING MEMORY}

Early investigations of cognition, particularly working memory, have indicated that acute cannabis use is associated with impairments in holding, manipulating and remembering information (38-40), with impairments typically remaining after other acute effects have subsided. Memory deficits are apparent in cannabis-using college students after $24 \mathrm{~h}$ of abstinence (41) and with heavy use (42), and these deficits are associated with duration of use $(43,44)$. Imaging has revealed altered activation during working memory tasks in regions such as the anterior cingulate and the thalamus even after sustained abstinence, both in adults $(45,46)$ and adolescents $(47)$. However, some data suggest that working memory impairments may precede cannabis use. In a 3-year examination of individuals with heavy cannabis use, no changes in working-memory-related brain activations (in the bilateral frontal poles and ventrolateral prefrontal, dorsolateral prefrontal, premotor, paracingulate, and inferior parietal cortices) were observed over time (48). Activation during an N-Back working memory task did not differ between individuals with and without cannabis use; however, greater activation statistically predicted escalation of cannabis use (49). While the weight of the literature points to working-memory impairments associated with cannabis use, preexisting vulnerabilities in working memory may exist and contribute to heavy use.

\section{THC AND CBD AND WORKING MEMORY}

THC has been proposed to be the primary culprit in workingmemory impairment associated with cannabis use. This has been demonstrated in animal models, where exposure to THC during adolescence resulted in learning impairments (50) that persisted into adulthood $(51,52)$. Acute examinations of THC in humans also suggest robust effects on memory. In a study where several memory tasks were administered to adults who were given acute oral THC, THC produced increased error rates alongside faster performance (53). Similarly, acute THC administration in healthy adults impaired performance on the Wisconsin Card Sorting Task (54). However, in both studies, performance returned to normal once effects of THC had subsided. Other work has examined neural correlates of attention and working memory in individuals given intravenous THC, where it was found that the P300 amplitude, related to responses to novel stimuli, was reduced and the level of reduction correlated with subjective reports of altered perceptions (55).

In contrast, $\mathrm{CBD}$ may enhance cognition, particularly in cannabis-using populations (56), schizophrenia (57-59) and neurodegenerative diseases $(60,61)$. CBD may reduce cognitive decrements seen in people who smoke cannabis (24). An animal study demonstrated that CBD improved memory among cognitively impaired rats (62). However, no effects were seen in rats who were not impaired. In humans, effects of acute use of vaped $\mathrm{CBD}$ and THC on attention or simulated driving may not differ between substances (63). Further, among abstinent individuals who smoke tobacco, acute CBD administration impaired working memory and increased errors of commission
TABLE 2 | Cannabis pharmacology - THC and CBD.

\begin{tabular}{ll}
\hline THC pharmacology & CBD pharmacology \\
\hline $\begin{array}{l}\text { Partial agonist of CB1 receptors, } \\
\text { 5HT3 receptors in CNS -> inhibition }\end{array}$ & $\begin{array}{l}\text { Lowers agonist efficacy of THC by } \\
\text { modulating CB1 receptors, binds to } \\
\text { of the release of acetylcholine and }\end{array}$ \\
$\begin{array}{l}\text { glutamate -> influencing } \\
\text { y-aminobutyric acid, }\end{array}$ & \\
N-methyl-D-aspartate, opioid and & \\
serotonin receptors. & \\
Ki values 5 (25) to 50 (26) & Ki values 4,300 (27) to 4,700 (28)
\end{tabular}

Ki values: measure of receptor affinity (high ki value = low affinity).

during N-back task performance (64). While evidence suggests that $\mathrm{CBD}$ may have promise for alleviating cognitive impairment in cannabis-using or clinical samples $(16,65)$, more research is needed on how it may influence working memory in other populations.

\section{CANNABIS AND INHIBITORY CONTROL}

Response inhibition and behavioral control, including over drugseeking, is important in addictive disorders (66). Impairments in inhibitory control may promote risky or disadvantageous decision-making in people who use cannabis (67). Poor inhibitory control during a Go/No-Go task and disadvantageous decision-making during a gambling task have been observed in cannabis-using young adults (68), consistent with findings among general adults (69). Differences in neural correlates of inhibitory control associated with cannabis use do not appear entirely consistent. Regions associated with inhibitory control show altered activation in people who use cannabis, with lower prefrontal activation as measured by fMRI, consistent with findings in alcohol and stimulant use disorders (14). During a Go/No-Go task in cannabis-using vs. non-cannabis-using adults, the former vs. latter group showed no differences in commission errors, but showed reduced error monitoring that was associated with reduction in activation of the anterior cingulate and right insula (70). Functional imaging during a Stop-Signal Task also revealed no differences in an inhibitory network activation between cannabis-using vs. non-cannabis-using individuals, but revealed that the former group had greater connectivity between a right frontal control network and substantia nigra/subthalamic nucleus network when functional connectivity was examined (71). In a study employing a Go/No-Go task in adolescents who were abstinent for two weeks, greater BOLD responses were observed in the left frontal cortex, left cingulate cortex, and the left thalamus during correct response inhibitions in those who used cannabis, though this may reflect greater inhibitory effort required to remain abstinent (72). EEG has revealed inhibition differences associated with cannabis use, with a reduction in the No-Go-related P3 component (a component associated with inhibitory control) of the event-related potential (ERP) when compared to non-drug-using or tobacco-using groups (73). Acute administration of cannabis before a Go/No-Go task also revealed a reduction in the No-Go P3 (74). While alterations 
in inhibitory control and its neural correlates appear linked to cannabis use, future work should continue examining this domain to specify precise relationships.

\section{THC AND CBD AND INHIBITORY CONTROL}

An animal model that investigated impulsivity using the 5choice serial-reaction-time test demonstrated that THC exposure resulted in increased motor impulsivity in rats that persisted after exposure ceased (75). An investigation of acute THC in humans revealed reduced activations in left inferior frontal regions that were associated with increased inhibition errors, impaired inhibition efficiency and transient psychotic symptoms (76). Acute effects of THC were also seen on an ERP associated with inhibition, the P300, and this reduction in P300 amplitude was not reversed by CBD (77). Further, an imaging study that investigated response inhibition after acute administration of either CBD or THC to healthy subjects revealed that while there were no performance differences between conditions, THC attenuated activation in the right inferior frontal and anterior cingulate gyri, regions associated with response inhibition. In contrast, $\mathrm{CBD}$ administration was associated with deactivation of the left temporal cortex and insula, demonstrating that CBD effects different regions, ones less typically associated with inhibition (78). Among people using CBD for treatmentresistant epilepsy, $\mathrm{CBD}$ altered connectivity patterns during an attentional-control task (79). It is possible that heterogeneity in findings outlined above may relate to types of cannabis used and differing effects of THC and CBD. One study has examined this, examining functional connectivity of executive, salience, and default-mode networks during resting state (80). Individuals were given cannabis containing THC (no CBD), cannabis containing THC with CBD and placebo. Reductions in functional connectivity were seen across networks for both cannabis types, and within the salience network, cannabis with THC and no CBD reduced connectivity relative to cannabis with CBD. Further, posterior cingulate connectivity was specifically impacted by cannabis with THC and no CBD, and this effect correlated with subjective "high" sensations. This study highlights that specific chemovars of cannabis, or use of different products containing $\mathrm{CBD}$, THC or both, may result in different effects on inhibitory control and cognition.

\section{CANNABIS AND REWARD PROCESSING}

Deficits in motivation and reward sensitivity may be pronounced with cannabis use, with several survey-based examinations linking self-reported lack of motivation and cannabis use (81). Blunted reward responses independent of alcohol or nicotine use have been observed with cannabis use, with greater blunting associated with more severe use $(82,83)$. Among cannabisusing relative to non-using subjects, reduced activation in the nucleus accumbens, caudate, left putamen, right inferior and medial frontal gyrus, superior frontal gyrus, and left cingulate was observed during monetary reward anticipation, with greater activation in the putamen observed during reward outcome (84).
Another study in cannabis-using adults employing the monetary incentive delay task found that those with cannabis use showed reduced activation in the left caudate and inferior frontal gyrus during rewarding feedback, and increased activation in the left caudate and bilateral inferior frontal gyrus when successfully avoiding losing money (85). In a separate study, greater ventral striatal activation was observed during losing outcomes in men with vs. without CUD (86). Relatively increased activation to rewarding outcomes was seen in the ventral striatum during reward anticipation in an independent group of cannabisusing subjects, and this activation was positively correlated with lifetime cannabis use amounts and durations (87). Cannabisusing vs. non-using individuals showed greater activation during gain trials in orbitofrontal cortex and cingulate gyrus and less activation in loss trials in orbitofrontal cortex, suggesting greater sensitivity to reward and reduced sensitivity to loss (88). However, adolescents who used cannabis only did not differ from adolescents who used tobacco only, alcohol only, cannabis+tobacco, cannabis+tobacco+alcohol, and no drugs in nucleus accumbens activation during anticipation of monetary reward or loss (89). More research is required to understand reward processing in relation to cannabis use, particularly given that cannabis and tobacco use often co-occur.

\section{THC AND CBD AND REWARD PROCESSING}

Acute THC administration has been associated with blunted ventral striatal activation during reward processing (90). THC is not readily self-administered, with rat models demonstrating aversiveness (91), though adolescent rats who consume THC show impairments in predicting rewards when reaching adulthood (92). THC's effects on reward processing may underlie reward-related findings seen in individuals who smoke cannabis. $\mathrm{CBD}$, however, has shown different relationships. CBD does not appear associated with addictive behaviors, and rather it may alleviate craving (93), reduce relapse potential (94), and decrease addiction severity for substance-use disorders (56), thereby reducing reinforcing effects of substances. Consistently, CBD administration to rats has resulted in less self-administration of cocaine (95) or methamphetamine (96). In humans, however, CBD administered via capsules did not change reinforcing subjective effects of smoked cannabis (97). CBD administered acutely before participants performed a monetary incentive delay task showed no differences in neural activations between CBD and placebo for either reward anticipation or reward receipt (98). Data on CBD and reward processing is thus somewhat inconsistent regarding whether or not it impacts THC's or other substance's effects on reward processing. Research on CBD's effects on reward processing is relatively scarce, especially with respect to longer-term effects on reward systems.

\section{CONCLUSIONS}

Simultaneous reduction in top-down control, including poorer inhibition and working memory, and blunted responsivity to non-drug rewards in people who use cannabis could set the 
stage for poorly controlled drug-seeking, consistent with dualprocess models of addiction. In addition, reward deficiency models suggest that blunted responses to non-drug rewards contribute to sensation-seeking and impulsivity, and, ultimately, to addictive behaviors (99). Similar processes may underlie cannabis- and other substance-use disorders (100). Altered reward responding may contribute to sensation-seeking while poorer inhibitory control may worsen tendencies to resist drug-seeking urges. Additionally, impaired working memory may contribute to disadvantageous decision-making, and thus increased tendencies to use cannabis. Chronic cannabis use, especially of strains/varieties high in THC, is associated with alterations in brain activation and behavior related to reward processing, working memory, and inhibitory control. It's effects on these neural correlates may provide a mechanistic explanation for why cannabis use, specifically of high-THC varieties, may lead to CUD and poorer quality of life (9). However, the potential impact of CBD on these domains appears subtle or non-existent, although more work on the effects of chronic CBD use is needed.

\section{FUTURE DIRECTIONS AND ADDITIONAL CONSIDERATIONS}

One aspect of cognition that may be specifically relevant to individuals with CUD and may supplement the dual-process model of addiction is emotional regulation. Negative affect is associated with craving for cannabis (101), and stress induced by lab-based social tasks has elicited craving for cannabis in people with CUD (102), particularly among people with low distress tolerance (103). Many individuals report using to alleviate distress (104), and edible CBD consumption may reduce social anxiety (105). Unfortunately, imaging studies of emotional regulation in CUD are scarce, and one group has identified decreased activation in bilateral frontal regions, including precentral and middle cingulate regions, during emotional reappraisal of negative affect in individuals with vs. without cannabis use $(106,107)$. Future work that investigates characteristics associated with cannabis use should also focus on regulation of emotion and how THC or CBD may influence affect.

Future research should focus on how types of cannabis administration, and use of different cannabinoids, may impact cognition, reward processing and inhibitory control. Vaping of cannabis flower or cannabis concentrates (e.g., THC) may release of higher concentrations of psychoactive ingredients (108, 109). Similarly, edibles derived from concentrates may generate slower onsets of effects (110) that may lead to greater ingestion of psychoactive ingredients that may generate longlasting effects than combustible use (4). Surveys of adolescents have identified different experiences among those who primarily smoke, vape, or consume edibles, with edible varieties described as most potent (111). Thus, investigating impacts of edibles and vaping on neural processes linked to addictive behaviors is important. Studying vaping may be particularly relevant as it has been associated with deadly illness related to use of THC oils and vitamin E acetate (112). Additionally, more study on the effects of CBD alone and in combination with THC is warranted, especially as legalization of cannabis becomes more widespread.

\section{AUTHOR CONTRIBUTIONS}

KPM wrote the first draft of the paper and worked with the co-author on subsequent drafts. Both authors contributed to the editorial process and have approved the final submitted version of the manuscript.

\section{FUNDING}

Funding for this work included National Institute of Health grants K01DA042937, R01 DA035058, and R01 DA039136. KPM receives support from K01DA042937. MP was supported by R01 DA035058, R01 DA039136, the National Center for Responsible Gaming, the Connecticut Council on Problem Gambling, and the Connecticut Department of Mental Health and Addiction Services. Beyond funding, the funding agencies had no further role in the writing of the report or in the decision to submit the paper for publication. This work was funded in part by the State of Connecticut, Department of Mental Health and Addiction Services, but this publication does not express the views of the Department of Mental Health and Addiction Services or the State of Connecticut. The views and opinions expressed are those of the authors.

\section{REFERENCES}

1. Miech RA, Johnston LD, O'Malley PM, Bachman JG, Schulenberg JE, Patrick ME. Monitoring the Future National Survey Results on Drug Use, 1975-2018: Volume I, Secondary School Students. Ann Arbor: University of Michigan; Institute for Social Research (2019). doi: 10.3998/2027.42/150622

2. Boccio CM, Jackson DB, Leal WE. Nicotine and marijuana attitudes among flavor-only vaping youth: new evidence from monitoring the future. Addict Behav. (2020) 102:106186. doi: 10.1016/j.addbeh.2019.106186

3. Mead A. Legal and regulatory issues governing cannabis and cannabisderived products in the United States. Front Plant Sci. (2019) 10:697. doi: $10.3389 /$ fpls.2019.00697

4. Meacham MC, Paul MJ, Ramo DE. Understanding emerging forms of cannabis use through an online cannabis community: an analysis of relative

post volume and subjective highness ratings. Drug Alcohol Depend. (2018) 188:364-9. doi: 10.1016/j.drugalcdep.2018.03.041

5. Schauer GL, King BA, Bunnell RE, Promoff G, McAfee TA. Toking, vaping, and eating for health or fun: marijuana use patterns in adults, U.S 2014. Am J Prev Med. (2016) 50:1-8. doi: 10.1016/j.amepre.2015.05.027

6. Solowij N. Peering through the haze of smoked vs vaporized cannabisto vape or not to vape? Jama Network Open. (2018) 1:e184838. doi: 10.1001/jamanetworkopen.2018.4838

7. Berg CJ, Stratton E, Schauer GL, Lewis M, Wang Y, Windle M, et al. Perceived harm, addictiveness, and social acceptability of tobacco products and marijuana among young adults: marijuana, hookah, and electronic cigarettes win. Subst Use Misuse. (2015) 50:79-89. doi: 10.3109/10826084.2014.958857

8. Roditis ML, Delucchi K, Chang A, Halpern-Felsher B. Perceptions of social norms and exposure to pro-marijuana messages are 
associated with adolescent marijuana use. Prev Med. (2016) 93:171-6. doi: 10.1016/j.ypmed.2016.10.013

9. Goldenberg M, IsHak WW, Danovitch I. Quality of life and recreational cannabis use. Am J Addict. (2017) 26:8-25. doi: 10.1111/ajad.12486

10. Hammond CJ, Chaney A, Hendrickson B, Sharma P. Cannabis use among U.S. adolescents in the era of marijuana legalization: a review of changing use patterns, comorbidity, and health correlates. Int Rev Psychiatry. (2020) 32:221-234. doi: 10.1080/09540261.2020.1713056

11. Blest-Hopley G, Giampietro V, Bhattacharyya S. Residual effects of cannabis use in adolescent and adult brains - a meta-analysis of fMRI studies. Neurosci Biobehav Rev. (2018) 88:26-41. doi: 10.1016/j.neubiorev.2018.03.008

12. Gunasekera B, Davies C, Martin-Santos R, Bhattacharyya S. The yin and yang of cannabis: a systematic review of human neuroimaging evidence of the differential effects of delta(9)-tetrahydrocannabinol and cannabidiol. Biol Psychiatry Cogn Neurosci Neuroimaging. (2020). doi: 10.1016/j.bpsc.2020.10.007. [Epub ahead of print].

13. Koob GF, Volkow ND. Neurocircuitry of addiction. Neuropsychopharmacology. (2010) 35:217-38. doi: 10.1038/npp.2009.110

14. Zilverstand A, Huang AS, Alia-Klein N, Goldstein RZ. Neuroimaging impaired response inhibition and salience attribution in human drug addiction: a systematic review. Neuron. (2018) 98:886-903. doi: 10.1016/j.neuron.2018.03.048

15. Bhattacharyya S, Crippa JA, Martin-Santos R, Winton-Brown T, Fusar-Poli P. Imaging the neural effects of cannabinoids: current status and future opportunities for psychopharmacology. Curr Pharm Des. (2009) 15:2603-14. doi: 10.2174/138161209788957465

16. Colizzi M, Bhattacharyya S. Does cannabis composition matter? differential effects of delta-9-tetrahydrocannabinol and cannabidiol on human cognition. Curr Addict Rep. (2017) 4:62-74. doi: 10.1007/s40429-017-0142-2

17. Salgado-Mendialdua V, Aguirre-Plans J, Guney E, Reig-Viader R, Maldonado R, Bayes A, et al. Delta9-tetrahydrocannabinol modulates the proteasome system in the brain. Biochem Pharmacol. (2018) 157:159-68. doi: 10.1016/j.bcp.2018.08.026

18. Phan KL, Angstadt M, Golden J, Onyewuenyi I, Popovska A, de Wit $H$. Cannabinoid modulation of amygdala reactivity to social signals of threat in humans. J Neurosci. (2008) 28:2313-9. doi: 10.1523/JNEUROSCI.5603-07.2008

19. Large M, Nielssen O. Daily use of high-potency cannabis is associated with an increased risk of admission and more intervention after first-episode psychosis. Evid Based Ment Health. (2017) 20:58. doi: $10.1136 /$ eb-2017-102630

20. Volkow ND, Swanson JM, Evins AE, DeLisi LE, Meier MH, Gonzalez $\mathrm{R}$, et al. Effects of cannabis use on human behavior, including cognition, motivation, and psychosis: a review. JAMA Psychiatry. (2016) 73:292-7. doi: 10.1001/jamapsychiatry.2015.3278

21. Murray RM, Quigley H, Quattrone D, Englund A, Di Forti M. Traditional marijuana, high-potency cannabis and synthetic cannabinoids: increasing risk for psychosis. World Psychiatry. (2016) 15:195-204. doi: 10.1002/wps.20341

22. Martin-Santos R, Crippa JA, Batalla A, Bhattacharyya S, Atakan Z, Borgwardt $\mathrm{S}$, et al. Acute effects of a single, oral dose of d9-tetrahydrocannabinol (THC) and cannabidiol (CBD) administration in healthy volunteers. Curr Pharm Des. (2012) 18:4966-79. doi: 10.2174/138161212802884780

23. Laprairie RB, Bagher AM, Kelly MEM, Denovan-Wright EM. Cannabidiol is a negative allosteric modulator of the cannabinoid CB1 receptor. $\mathrm{Br} \mathrm{J}$ Pharmacol. (2015) 172:4790-805. doi: 10.1111/bph.13250

24. Henquet C, Kuepper R. Does cannabidiol protect against the negative effects of THC? Br J Psychiatry. (2010) 197:259-60. doi: 10.1192/bjp.bp.110.081380

25. Iwamura $\mathrm{H}$, Suzuki $\mathrm{H}$, Ueda $\mathrm{Y}$, Kaya $\mathrm{T}$, Inaba $\mathrm{T}$. In vitro and in vivo pharmacological characterization of JTE-907, a novel selective ligand for cannabinoid CB2 receptor. J Pharmacol Exp Ther. (2001) 296:420-5.

26. Felder CC, Joyce KE, Briley EM, Mansouri J, Mackie K, Blond O, et al. Comparison of the pharmacology and signal transduction of the human cannabinoid CB1 and CB2 receptors. Mol Pharmacol. (1995) 48:443-50.

27. Showalter VM, Compton DR, Martin BR, Abood ME. Evaluation of binding in a transfected cell line expressing a peripheral cannabinoid receptor (CB2): identification of cannabinoid receptor subtype selective ligands. J Pharmacol Exp Ther. (1996) 278:989-99.
28. Thomas A, Ross RA, Saha B, Mahadevan A, Razdan RK, Pertwee RG. 6"-Azidohex-2"-yne-cannabidiol: a potential neutral, competitive cannabinoid CB1 receptor antagonist. Eur J Pharmacol. (2004) 487:213-21. doi: 10.1016/j.ejphar.2004.01.023

29. Rosenthaler S, Pohn B, Kolmanz C, Huu CN, Krewenka C, Huber A, et al. Differences in receptor binding affinity of several phytocannabinoids do not explain their effects on neural cell cultures. Neurotoxicol Teratol. (2014) 46:49-56. doi: 10.1016/j.ntt.2014.09.003

30. Babalonis S, Haney M, Malcolm RJ, Lofwall MR, Votaw VR, Sparenborg $S$, et al. Oral cannabidiol does not produce a signal for abuse liability in frequent marijuana smokers. Drug Alcohol Depend. (2017) 172:9-13. doi: 10.1016/j.drugalcdep.2016.11.030

31. Schubart CD, Sommer IE, van Gastel WA, Goetgebuer RL, Kahn RS, Boks MP. Cannabis with high cannabidiol content is associated with fewer psychotic experiences. Schizophrenia Res. (2011) 130:216-21. doi: 10.1016/j.schres.2011.04.017

32. Viudez-Martinez A, Garcia-Gutierrez MS, Medrano-Relinque J, Navarron CM, Navarrete F, Manzanares J. Cannabidiol does not display drug abuse potential in mice behavior. Acta Pharmacol Sinica. (2019) 40:358-64. doi: 10.1038/s41401-018-0032-8

33. Noel X, Brevers D, Bechara A. A neurocognitive approach to understanding the neurobiology of addiction. Curr Opin Neurobiol. (2013) 23:632-8. doi: 10.1016/j.conb.2013.01.018

34. Geier CF, Terwilliger R, Teslovich T, Velanova K, Luna B. Immaturities in reward processing and its influence on inhibitory control in adolescence. Cereb Cortex. (2010) 20:1613-29. doi: 10.1093/cercor/ bhp225

35. Zhou F, Zimmermann K, Xin F, Scheele D, Dau W, Banger M, et al. Shifted balance of dorsal versus ventral striatal communication with frontal reward and regulatory regions in cannabis-dependent males. Hum Brain Mapp. (2018) 39:5062-73. doi: 10.1002/hbm.24345

36. Panwar K, Rutherford HJV, Mencl WE, Lacadie CM, Potenza MN, Mayes LC. Differential associations between impulsivity and risk-taking and brain activations underlying working memory in adolescents. Addict Behav. (2014) 39:1606-21. doi: 10.1016/j.addbeh.2013.12.007

37. Secades-Villa R, Garcia-Rodriguez O, Jin CJ, Wang S, Blanco C. Probability and predictors of the cannabis gateway effect: a national study. Int J Drug Policy. (2015) 26:135-42. doi: 10.1016/j.drugpo.2014.07.011

38. Heishman SJ, Arasteh K, Stitzer ML. Comparative effects of alcohol and marijuana on mood, memory, and performance. Pharmacol Biochem Behav. (1997) 58:93-101. doi: 10.1016/S0091-3057(96)00456-X

39. Miller LL, McFarland DJ, Cornett TL, Brightwell DR, Wikler A. Marijuana: effects on free recall and subjective organization of pictures and words. Psychopharmacology. (1977) 55:257-62. doi: 10.1007/BF00497857

40. Tinklenberg JR, Melges FT, Hollister LE, Gillespie HK. Marijuana and immediate memory. Nature. (1970) 226:1171-2. doi: 10.1038/2261171b0

41. Pope HG, YurgelunTodd D. The residual cognitive effects of heavy marijuana use in college students. JAMA. (1996) 275:521-7. doi: 10.1001/jama.1996.03530310027028

42. Fisk JE, Montgomery C. Real-world memory and executive processes in cannabis users and non-users. J Psychopharmacol. (2008) 22:727-36. doi: $10.1177 / 0269881107084000$

43. Solowij N, Michie PT, Fox AM. Differential impairments of selective attention due to frequency and duration of cannabis use. Biol Psychiatry. (1995) 37:731-9. doi: 10.1016/0006-3223(94)00178-6

44. Solowij N, Stephens RS, Roffman RA, Babor T, Kadden R, Miller M, et al. Cognitive functioning of long-term heavy cannabis users seeking treatment. JAMA. (2002) 287:1123-31. doi: 10.1001/jama.287.9.1123

45. Jager G, Kahn RS, Van den Brink W, Van Ree JM, Ramsey NF. Long-term effects of frequent cannabis use on working memory and attention: an fMRI study. Psychopharmacology. (2006) 185:358-68. doi: 10.1007/s00213-005-0298-7

46. Kanayama G, Rogowska J, Pope HG, Gruber SA, Yurgelun-Todd DA. Spatial working memory in heavy cannabis users: a functional magnetic resonance imaging study. Psychopharmacology. (2004) 176:239-47. doi: 10.1007/s00213-004-1885-8

47. Padula CB, Schweinsburg AD, Tapert SF. Spatial working memory performance and fMRI activation interaction in abstinent 
adolescent marijuana users. Psychol Addict Behav. (2007) 21:478-87. doi: 10.1037/0893-164X.21.4.478

48. Cousijn J, Vingerhoets WA, Koenders L, de Haan L, van den Brink W, Wiers RW, et al. Relationship between working-memory network function and substance use: a 3-year longitudinal fMRI study in heavy cannabis users and controls. Addict Biol. (2014) 19:282-93. doi: 10.1111/adb.12111

49. Cousijn J, Wiers RW, Ridderinkhof KR, van den Brink W, Veltman DJ, Goudriaan AE. Effect of baseline cannabis use and workingmemory network function on changes in cannabis use in heavy cannabis users: a prospective fMRI study. Hum Brain Mapp. (2014) 35:2470-82. doi: $10.1002 / \mathrm{hbm} .22342$

50. Cha YM, White AM, Kuhn CM, Wilson WA, Swartzwelder HS. Differential effects of delta9-THC on learning in adolescent and adult rats. Pharmacol Biochem Behav. (2006) 83:448-55. doi: 10.1016/j.pbb.2006.03.006

51. Quinn HR, Matsumoto I, Callaghan PD, Long LE, Arnold JC, Gunasekaran N, et al. Adolescent rats find repeated Delta(9)-THC less aversive than adult rats but display greater residual cognitive deficits and changes in hippocampal protein expression following exposure. Neuropsychopharmacology. (2008) 33:1113-26. doi: 10.1038/sj.npp.1301475

52. Rubino T, Realini N, Braida D, Guidi S, Capurro V, Vigano D, et al. Changes in hippocampal morphology and neuroplasticity induced by adolescent THC treatment are associated with cognitive impairment in adulthood. Hippocampus. (2009) 19:763-72. doi: 10.1002/hipo.20554

53. Curran HV, Brignell C, Fletcher S, Middleton P, Henry J. Cognitive and subjective dose-response effects of acute oral Delta 9-tetrahydrocannabinol (THC) in infrequent cannabis users. Psychopharmacology (Berl). (2002) 164:61-70. doi: 10.1007/s00213-002-1169-0

54. Weinstein A, Brickner O, Lerman H, Greemland M, Bloch M, Lester H, et al. A study investigating the acute dose-response effects of $13 \mathrm{mg}$ and 17 mg Delta 9- tetrahydrocannabinol on cognitive-motor skills, subjective and autonomic measures in regular users of marijuana. J Psychopharmacol. (2008) 22:441-51. doi: 10.1177/0269881108088194

55. D'Souza DC, Fridberg DJ, Skosnik PD, Williams A, Roach B, Singh N, et al. Dose-related modulation of event-related potentials to novel and target stimuli by intravenous Delta(9)-THC in humans. Neuropsychopharmacology. (2012) 37:1632-46. doi: 10.1038/npp.2012.8

56. Batalla A, Janssen H, Gangadin SS, Bossong MG. The potential of cannabidiol as a treatment for psychosis and addiction: who benefits most? A systematic review. J Clin Med. (2019) 8:1058. doi: 10.3390/jcm8071058

57. Davies C, Bhattacharyya S. Cannabidiol as a potential treatment for psychosis. Therapeutic Adv Psychopharmacol. (2019) 9:51-64. doi: $10.1177 / 2045125319881916$

58. Deiana S, Zamberletti E. Cannabidiol as a potential novel therapeutic agent for psychotic disorders. In: Compton MT, Manseau MW, editors. The Complex Connection Between Cannabis and Schizophrenia. Elsevier Academic Press (2018). p. 309-39. doi: 10.1016/B978-0-12-804791-0.00014-8

59. Kopelli E, Samara M, Siargkas A, Goulas A, Papazisis G, Chourdakis M. The role of cannabidiol oil in schizophrenia treatment. A systematic review and meta-analysis. Psychiatry Res. (2020) 291:113246. doi: 10.1016/j.psychres.2020.113246

60. Mori MA, Meyer E, Soares LM, Milani H, Guimaraes FS, de Oliveira RMW. Cannabidiol reduces neuroinflammation and promotes neuroplasticity and functional recovery after brain ischemia. Prog Neuropsychopharmacol Biol Psychiatry. (2017) 75:94-105. doi: 10.1016/j.pnpbp.2016.11.005

61. Watt G, Karl T. In vivo evidence for therapeutic properties of cannabidiol (CBD) for Alzheimer's disease. Front Pharmacol. (2017) 8:10.3389. doi: 10.3389/fphar.2017.00020

62. Fagherazzi EV, Garcia VA, Maurmann N, Bervanger T, Halmenschlager LH, Busato SB, et al. Memory-rescuing effects of cannabidiol in an animal model of cognitive impairment relevant to neurodegenerative disorders. Psychopharmacology. (2012) 219:1133-40. doi: 10.1007/s00213-011-2449-3

63. Arkell TR, Lintzeris N, Kevin RC, Ramaekers JG, Vandrey R, Irwin C, et al. Cannabidiol (CBD) content in vaporized cannabis does not prevent tetrahydrocannabinol (THC)-induced impairment of driving and cognition. Psychopharmacology. (2019) 236:2713-24. doi: 10.1007/s00213-019-05246-8

64. Hindocha C, Freeman TP, Grabski M, Crudgington H, Davies AC, Stroud JB, et al. The effects of cannabidiol on impulsivity and memory during abstinence in cigarette dependent smokers. Sci Rep. (2018) 8:7568. doi: 10.1038/s41598-018-25846-2

65. Colizzi M, Ruggeri M, Bhattacharyya S. Unraveling the intoxicating and therapeutic effects of cannabis ingredients on psychosis and cognition. Front Psychol. (2020) 11:833. doi: 10.3389/fpsyg.2020.00833

66. Garavan H, Stout JC. Neurocognitive insights into substance abuse. Trends in Cognitive Sciences. (2005) 9:195-201. doi: 10.1016/j.tics.2005.02.008

67. De Bellis MD, Wang L, Bergman SR, Yaxley RH, Hooper SR, Huettel SA. Neural mechanisms of risky decision-making and reward response in adolescent onset cannabis use disorder. Drug Alcohol Depend. (2013) 133:134-45. doi: 10.1016/j.drugalcdep.2013.05.020

68. Moreno M, Estevez AF, Zaldivar F, Montes JM, Gutierrez-Ferre VE, Esteban $\mathrm{L}$, et al. Impulsivity differences in recreational cannabis users and binge drinkers in a University population. Drug Alcohol Depend. (2012) 124:35562. doi: 10.1016/j.drugalcdep.2012.02.011

69. Whitlow CT, Liguori A, Livengood LB, Hart SL, Mussat-Whitlow BJ, Lamborn CM, et al. Long-term heavy marijuana users make costly decisions on a gambling task. Drug Alcohol Depend. (2004) 76:107-11. doi: 10.1016/j.drugalcdep.2004.04.009

70. Hester R, Nestor L, Garavan H. Impaired error awareness and anterior cingulate cortex hypoactivity in chronic cannabis users. Neuropsychopharmacology. (2009) 34:2450-8. doi: 10.1038/npp.2009.67

71. Filbey F, Yezhuvath U. Functional connectivity in inhibitory control networks and severity of cannabis use disorder. Am J Drug Alcohol Abuse. (2013) 39:382-91. doi: 10.3109/00952990.2013.841710

72. Wallace AL, Maple KE, Barr AT, Lisdahl KM. BOLD responses to inhibition in cannabis-using adolescents and emerging adults after 2 weeks of monitored cannabis abstinence. Psychopharmacology (Berl). (2020) 237:3259-68. doi: 10.1007/s00213-020-05608-7

73. Fridberg DJ, Skosnik PD, Hetrick WP, O’Donnell BF. Neural correlates of performance monitoring in chronic cannabis users and cannabisnaive controls. Journal of Psychopharmacology. (2013) 27:515-25. doi: $10.1177 / 0269881113477745$

74. Spronk DB, De Bruijn ER, van Wel JH, Ramaekers JG, Verkes RJ. Acute effects of cocaine and cannabis on response inhibition in humans: an ERP investigation. Addict Biol. (2016) 21:1186-98. doi: 10.1111/adb.12274

75. Irimia C, Polis IY, Stouffer D, Parsons LH. Persistent effects of chronic Delta9-THC exposure on motor impulsivity in rats. Psychopharmacology (Berl). (2015) 232:3033-43. doi: 10.1007/s00213-015-3942-x

76. Bhattacharyya S, Atakan Z, Martin-Santos R, Crippa JA, Kambeitz J, Malhi $S$, et al. Impairment of inhibitory control processing related to acute psychotomimetic effects of cannabis. Eur Neuropsychopharmacol. (2015) 25:26-37. doi: 10.1016/j.euroneuro.2014.11.018

77. Roser P, Juckel G, Rentzsch J, Nadulski T, Gallinat J, Stadelmann AM. Effects of acute oral Delta9-tetrahydrocannabinol and standardized cannabis extract on the auditory P300 event-related potential in healthy volunteers. Eur Neuropsychopharmacol. (2008) 18:569-77. doi: 10.1016/j.euroneuro.2008.04.008

78. Borgwardt SJ, Allen P, Bhattacharyya S, Fusar-Poli P, Crippa JA, Seal ML, et al. Neural basis of Delta-9-tetrahydrocannabinol and cannabidiol: effects during response inhibition. Biol Psychiatry. (2008) 64:966-73. doi: 10.1016/j.biopsych.2008.05.011

79. Allendorfer JB, Nenert R, Bebin EM, Gaston TE, Grayson LE, Hernando $\mathrm{KA}$, et al. fMRI study of cannabidiol-induced changes in attention control in treatment-resistant epilepsy. Epilepsy Behav. (2019) 96:114-21. doi: 10.1016/j.yebeh.2019.04.008

80. Wall MB, Pope R, Freeman TP, Kowalczyk OS, Demetriou L, Mokrysz C, et al. Dissociable effects of cannabis with and without cannabidiol on the human brain's resting-state functional connectivity. J Psychopharmacol. (2019) 33:822-30. doi: 10.1177/0269881119841568

81. Pacheco-Colon I, Limia JM, Gonzalez R. Nonacute effects of cannabis use on motivation and reward sensitivity in humans: a systematic review. Psychol Addict Behav. (2018) 32:497-507. doi: 10.1037/adb00 00380

82. Heitzeg MM, Cope LM, Martz ME, Hardee JE, Zucker RA. Brain activation to negative stimuli mediates a relationship between adolescent marijuana use and later emotional functioning. Dev Cognitive Neurosci. (2015) 16:71-83. doi: $10.1016 /$ j.den.2015.09.003 
83. Martz ME, Trucco EM, Cope LM, Hardee JE, Jester JM, Zucker RA, et al. Association of marijuana use with blunted nucleus accumbens response to reward anticipation. JAMA Psychiatry. (2016) 73:838-44. doi: 10.1001/jamapsychiatry.2016.1161

84. van Hell HH, Vink M, Ossewaarde L, Jager G, Kahn RS, Ramsey NF. Chronic effects of cannabis use on the human reward system: an fMRI study. Eur Neuropsychopharmacol. (2010) 20:153-63. doi: 10.1016/j.euroneuro.2009.11.010

85. Enzi B, Lissek S, Edel MA, Tegenthoff M, Nicolas V, Scherbaum N, et al. Alterations of monetary reward and punishment processing in chronic cannabis users: an FMRI study. PLoS ONE. (2015) 10:e0119150. doi: 10.1371/journal.pone.0119150

86. Yip SW, DeVito EE, Kober H, Worhunsky PD, Carroll KM, Potenza MN. Pretreatment measures of brain structure and reward-processing brain function in cannabis dependence: an exploratory study of relationships with abstinence during behavioral treatment. Drug Alcohol Depend. (2014) 140:33-41. doi: 10.1016/j.drugalcdep.2014.03.031

87. Nestor L, Hester R, Garavan H. Increased ventral striatal BOLD activity during non-drug reward anticipation in cannabis users. Neuroimage. (2010) 49:1133-43. doi: 10.1016/j.neuroimage.2009.07.022

88. Filbey FM, Dunlop J, Myers US. Neural effects of positive and negative incentives during marijuana withdrawal. PLoS ONE. (2013) 8:e61470. doi: 10.1371/journal.pone.0061470

89. Karoly HC, Bryan AD, Weiland BJ, Mayer A, Dodd A, Ewing SWF. Does incentive-elicited nucleus accumbens activation differ by substance of abuse? An examination with adolescents. Dev Cognitive Neurosci. (2015) 16:5-15. doi: 10.1016/j.dcn.2015.05.005

90. Jansma JM, van Hell HH, Vanderschuren LJ, Bossong MG, Jager G, Kahn RS, et al. THC reduces the anticipatory nucleus accumbens response to reward in subjects with a nicotine addiction. Transl Psychiatry. (2013) 3:e234. doi: 10.1038/tp.2013.6

91. Parker LA, Gillies T. THC-induced place and taste aversions in Lewis and Sprague-Dawley rats. Behav Neurosci. (1995) 109:71-8. doi: 10.1037/0735-7044.109.1.71

92. Kruse LC, Cao JK, Viray K, Stella N, Clark JJ. Voluntary oral consumption of Delta(9)-tetrahydrocannabinol by adolescent rats impairs reward-predictive cue behaviors in adulthood. Neuropsychopharmacology. (2019) 44:1406-14. doi: 10.1038/s41386-019-0387-7

93. Hurd YL. Cannabidiol for the reduction of cue-induced craving and anxiety in drug-abstinent individuals with heroin use disorder: a doubleblind randomized placebo-controlled trial (vol, pg). Am J Psychiatry. (2020) 177:641-641. doi: 10.1176/appi.ajp.2020.18101191correction

94. Gonzalez-Cuevas G, Martin-Fardon R, Kerr TM, Stouffer DG, Parsons LH, Hammell DC, et al. Unique treatment potential of cannabidiol for the prevention of relapse to drug use: preclinical proof of principle. Neuropsychopharmacology. (2018) 43:2036-45. doi: 10.1038/s41386-018-0050-8

95. Galaj E, Bi GH, Yang HJ, Xi ZX. Cannabidiol attenuates the rewarding effects of cocaine in rats by CB2, 5-HT1A and TRPV1 receptor mechanisms. Neuropharmacology. (2020) 167:107740. doi: 10.1016/j.neuropharm.2019.107740

96. Hay GL, Baracz SJ, Everett NA, Roberts J, Costa PA, Arnold JC, et al. Cannabidiol treatment reduces the motivation to self-administer methamphetamine and methamphetamine-primed relapse in rats. J Psychopharmacol. (2018) 32:1369-78. doi: 10.1177/02698811187 99954

97. Haney M, Malcolm RJ, Babalonis S, Nuzzo PA, Cooper ZD, Bedi G, et al. Oral cannabidiol does not alter the subjective, reinforcing or cardiovascular effects of smoked cannabis. Neuropsychopharmacology. (2016) 41:1974-82. doi: 10.1038/npp.2015.367

98. Lawn W, Hill J, Hindocha C, Yim J, Yamamori Y, Jones G, et al. The acute effects of cannabidiol on the neural correlates of reward anticipation and feedback in healthy volunteers. J Psychopharmacol. (2020) 34:969-80. doi: 10.1177/0269881120944148

99. Blum K, Braverman ER, Holder JM, Lubar JF, Monastra VJ, Miller D, et al. Reward deficiency syndrome: a biogenetic model for the diagnosis and treatment of impulsive, addictive, and compulsive behaviors. J Psychoactive Drugs. (2000) 32 (Suppl. i-iv):1-112. doi: 10.1080/02791072.2000.107 36099
100. Luijten M, Machielsen MWJ, Veltman DJ, Hester R, de Haan LHA. Systematic review of ERP and fMRI studies investigating inhibitory control and error processing in people with substance dependence and behavioural addictions. J Psychiatry Neurosci. (2014) 39:149-69. doi: 10.1503/jpn.130052

101. Manning K, Paulus DJ, Hogan JBD, Buckner JD, Farris SG, Zvolensky MJ. Negative affectivity as a mechanism underlying perceived distress tolerance and cannabis use problems, barriers to cessation, and self-efficacy for quitting among urban cannabis users. Addict Behav. (2018) 78:216-22. doi: 10.1016/j.addbeh.2017.11.041

102. Buckner JD, Zvolensky MJ, Ecker AH, Jeffries ER. Cannabis craving in response to laboratory-induced social stress among racially diverse cannabis users: the impact of social anxiety disorder. J Psychopharmacol. (2016) 30:363-9. doi: 10.1177/0269881116629115

103. Buckner JD, Walukevich Dienst K, Zvolensky MJ. Distress tolerance and cannabis craving: The impact of laboratory-induced distress. Exp Clin Psychopharmacol. (2019) 27:38-44. doi: 10.1037/pha0000231

104. Dorard G, Berthoz S, Phan O, Corcos M, Bungener C. Affect dysregulation in cannabis abusers: a study in adolescents and young adults. Eur Child Adolesc Psychiatry. (2008) 17:274-82. doi: 10.1007/s00787-007-0663-7

105. Masataka N. Anxiolytic effects of repeated cannabidiol treatment in teenagers with social anxiety disorders. Front Psychol. (2019) 10:2466. doi: 10.3389/fpsyg.2019.02466

106. Zimmermann K, Walz C, Derckx RT, Kendrick KM, Weber B, Dore B, et al. Emotion regulation deficits in regular marijuana users. Hum Brain Mapp. (2017) 38:4270-9. doi: 10.1002/hbm.23671

107. Zimmermann K, Yao S, Heinz M, Zhou F, Dau W, Banger M, et al. Altered orbitofrontal activity and dorsal striatal connectivity during emotion processing in dependent marijuana users after 28 days of abstinence. Psychopharmacology (Berl). (2018) 235:849-59. doi: 10.1007/s00213-017-4803-6

108. Spindle TR, Cone EJ, Schlienz NJ. Acute effects of smoked and vaporized cannabis in healthy adults who infrequently use cannabis: a crossover trial (vol 1, e184841, 2018). JAMA Network Open. (2018) 1:e184841. doi: 10.1001/jamanetworkopen.2018.4841

109. Spindle TR, Cone EJ, Schlienz NJ, Mitchell JM, Bigelow GE, Flegel R, et al. Acute pharmacokinetic profile of smoked and vaporized cannabis in human blood and oral fluid. J Anal Toxicol. (2019) 43:233-58. doi: $10.1093 /$ jat/bky104

110. Lamy FR, Daniulaityte R, Sheth A, Nahhas RW, Martins SS, Boyer EW, et al. "Those edibles hit hard": exploration of twitter data on cannabis edibles in the U.S. Drug Alcohol Depend. (2016) 164:64-70. doi: 10.1016/j.drugalcdep.2016.04.029

111. Ewusi Boisvert E, Bae D, Pang RD, Davis JP, Kelley-Quon LI, BarringtonTrimis JL, et al. Subjective effects of combustible, vaporized, and edible cannabis: results from a survey of adolescent cannabis users. Drug Alcohol Depend. (2020) 206:107716. doi: 10.1016/j.drugalcdep.2019.107716

112. CDC. (2019). Outbreak of Lung Injury Associated with the Use of E-Cigarette, or Vaping, Products. Available online at: https://www.cdc.gov/tobacco/basic information/e-cigarettes/severe-lung-disease.html

Conflict of Interest: MP has consulted for and advised Opiant Pharmaceuticals, Idorsia Pharmaceuticals, AXA, Game Day Data and the Addiction Policy Forum; has received research support from the Mohegan Sun Casino, Connecticut Council on Problem Gambling and National Center for Responsible Gaming; has participated in surveys, mailings or telephone consultations related to drug addiction, impulse control disorders or other health topics; and has consulted for law offices and gambling entities on issues related to impulse control or addictive disorders.

The remaining author declares that the research was conducted in the absence of any commercial or financial relationships that could be construed as a potential conflict of interest.

Copyright (C) 2021 Morie and Potenza. This is an open-access article distributed under the terms of the Creative Commons Attribution License (CC BY). The use, distribution or reproduction in other forums is permitted, provided the original author(s) and the copyright owner(s) are credited and that the original publication in this journal is cited, in accordance with accepted academic practice. No use, distribution or reproduction is permitted which does not comply with these terms. 